Y

\title{
CFD Proposals for the Layout of Air Vents for Realization of Underfloor Air Cavity Created from Special Fittings
}

\author{
Tomáš Renčko, Anna Sedláková \\ Technical University of Košice \\ Civil Engineering Faculty, Institute of Architectural Engineering \\ e-mail: tomas.rencko@tuke.sk, anna.sedlakova@tuke.sk
}

\begin{abstract}
In basement acting humidity can be removed using ventilated flooring created from special fittings. Particular attention should be paid to the design layout of inlet and outlet of openings. The aim of the correct proposal is the even distribution of air flow over the whole surface of the cavity. To achieve this state and to objective evaluate the air flow in the gaps, which are made up of shaped objects, the work uses CFD simulations. Based on computational simulations, structural designs of underfloor air cavities created using special fittings are designed. As results are the proposals for the layout of air vents for historic buildings for realization in Kosice.
\end{abstract}

Key words: humidity, dehumidifying, historic buildings, ventilated air cavities, CFD

\section{Model example}

A model example considers a house of historical context (Fig. 1, 2, 3) with an additional applied ventilated underfloor air cavity. The geometry and structural composition of the house is typical of many buildings scattered throughout the territory of the Slovak Republic [1].

The underfloor air cavity is designed from special Modulo fittings [2]. The air cavity height of $200 \mathrm{~mm}$ is often used in practice. The layout of intake / exhaust vents under the general principles stated by the manufacturer of these and similar types of products. Specifically, placed in the corners and at intervals from 3 to $5 \mathrm{~m}$. Vent openings made from PVC pipe ø $100 \mathrm{~mm}$ in practice is also often used.

In the event that the interior of the house is artificially heated during the winter, appropriately positioned thermal insulation will be required in accordance with the requirements of STN 73 0540-2 [3] and calculations determined by the boundary conditions of STN 73 0540-3 [4]. This solution reduces heat losses, but the evaluation of annual energy consumptions according to STN EN ISO 13790/NA [5] procedures and the evaluation of thermal bridges according to EN ISO 10211 [6] are in this case (historic building) inadequate. 


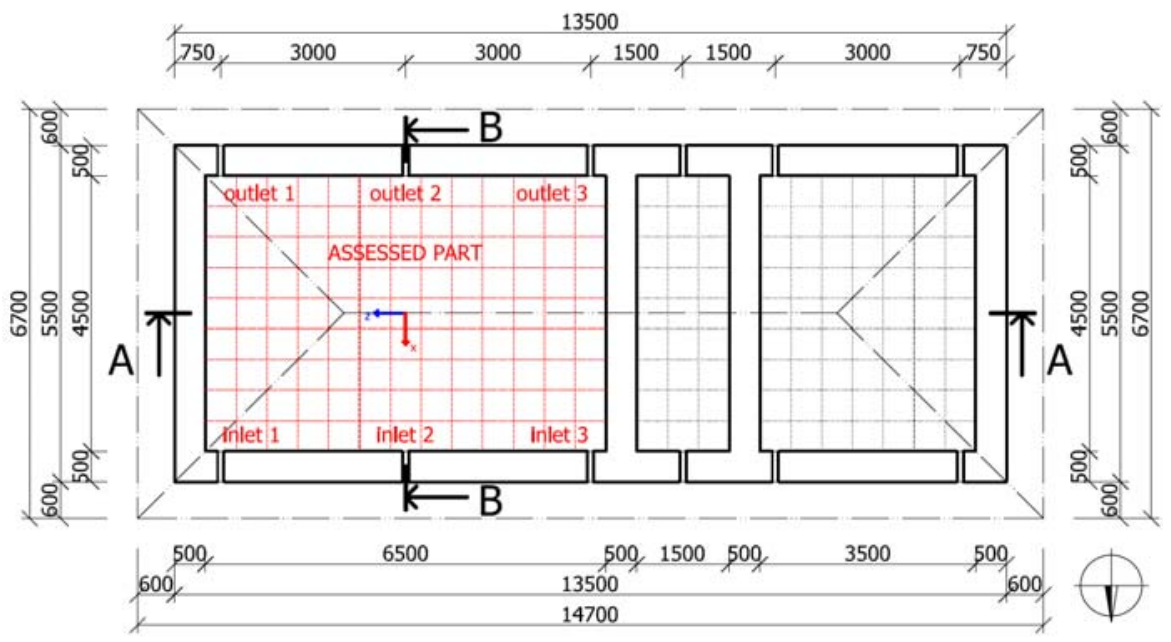

Figure 1: Ground plane of house [7]

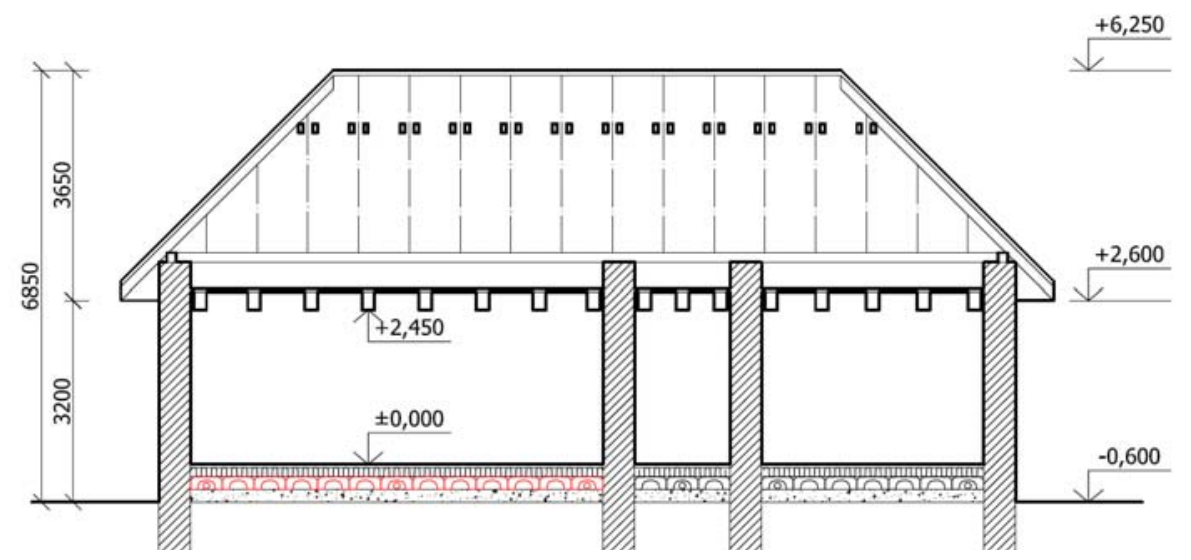

Figure 2: Cross section A-A [7]

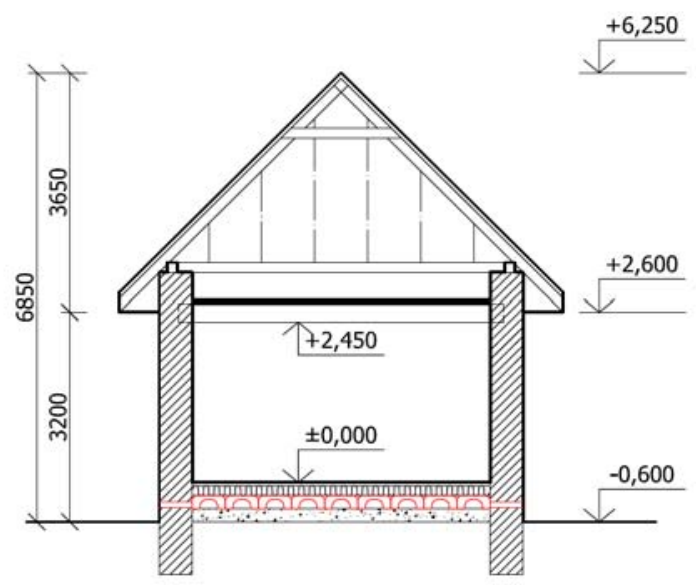

Figure 3: Cross section B-B [7] 


\section{Simulation models - Design from manufacturers}

ANSYS CFX is used to assess the underfloor ventilation model example (Fig. 1, 2, 3). Of the two completed simulations, the first overall geometry of a modeled house, ascertains the actual pressure on the walls due to wind effects. Results from the first simulation are applied as boundary conditions, where the geometric model represents the underfloor air cavity.

For creating the first simulation model is used overall simplified geometry of in Fig. 1, 2, 3. Modeled house was surrounded by air and subsequently excised so that alone model of air remains. The overall geometric model of the house is simulated by a wind flow of $\mathrm{v}_{10}=2.5$ m.s ${ }^{-1}$ (median of air velocity for the area of Košice) induced at the north face, which increases with height. Solved total area consists of the air at a temperature of $10^{\circ} \mathrm{C}$ (median of air temperature for the area of Košice). To solution was used SST turbulence model (good for wind engineering). Boundary conditions are illustrated on Fig. 4. Specifically:

„inlet" - Boundary Type: Inlet, Normal speed: Through Expressions set wind profile

$$
v_{\text {prof }}=v_{10}\left(\frac{h}{h_{10}}\right)^{\infty}
$$

where $\mathrm{v}_{10}=2.5 \mathrm{~m} \cdot \mathrm{s}^{-1}, h=y, \mathrm{~h}_{10}=10 \mathrm{~m}, \alpha=0.15$ (open country with low vegetation)

„outlet“ - Boundary Type: Outlet: Relative pressure $=0 \mathrm{~Pa}$

„sky“ - Boundary Type: Opening: Relative pressure $=0 \mathrm{~Pa}$

„sidewall““ - Boundary Type: Wall: Free Slip Wall

„ground“" - Boundary Type: Wall: No Slip Wall, Roug Wall =0,05 m (tall grass)

„house“6 - Boundary Type: Wall: No Slip Wall, Rough Wall = 0,01 m (roof surface)

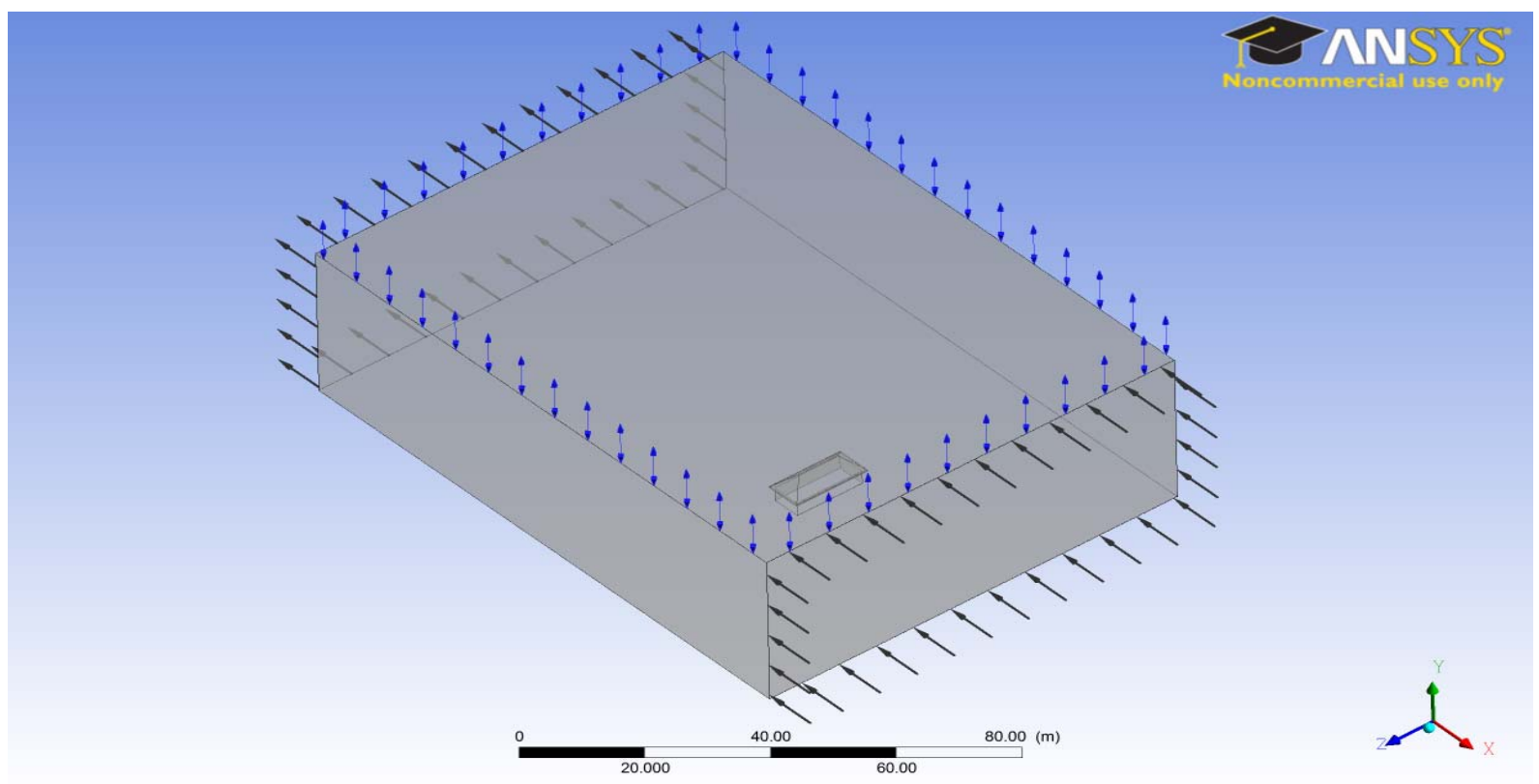

Figure 4: First simulation model [7] 
The modeling process is realized due to changes in pressure along the length and height of the windward and leeward sides. Modeling an air flow with constant speed of $2.5 \mathrm{~m} . \mathrm{s}^{-1}$ for each inlet (in other simulations), is deemed inappropriate.

Fig. 5 illustrates the pressure induced on the windward (north) side of the church. It is visible that wall pressure waves are symmetrical, changing in length and height according to the wall. Inlet pressure increases towards the centre of the ventilation's inlets. Fig. 6 reveals the air suction on the leeward (south) side.

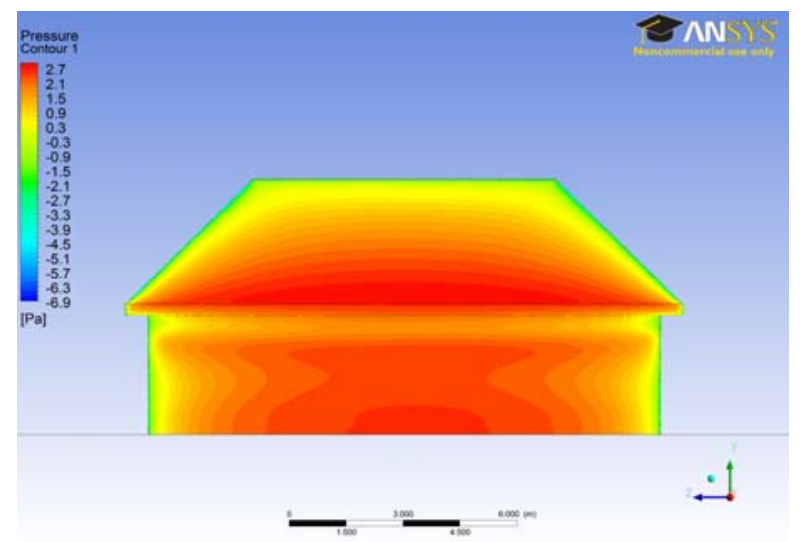

Figure 5: Pressures on windward side [7]

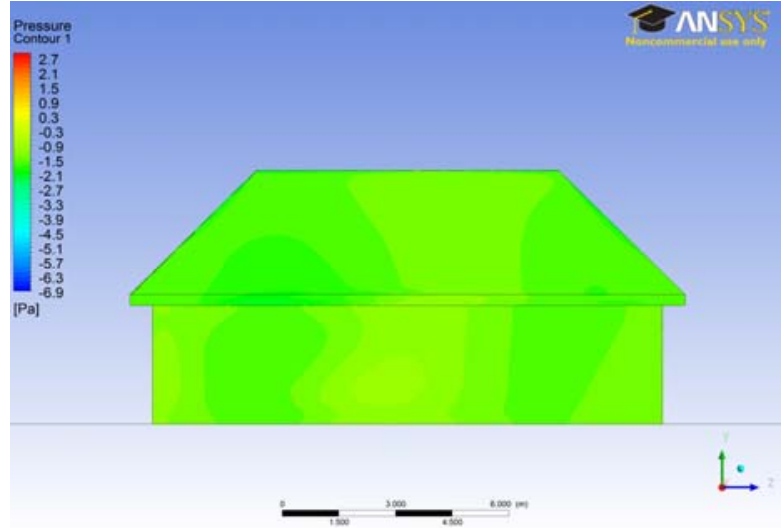

Figure 6: Pressures on leeward side [7]

The specifying of input boundary conditions for the second simulation (independent cavity) requires the logging of exact pressure values at the intake and exhaust openings. For this purpose exact values of static pressures subtracted are.

Windward and leeward side, from the first to the last hole is divided into eight equal parts. Curves of air pressures are shown in Fig. 7. Proposed intake / exhaust vents are at point no. 1, no 3 and no 5 (see in graph). Specific values of input / output pressure (boundary conditions) are described below in second simulation.

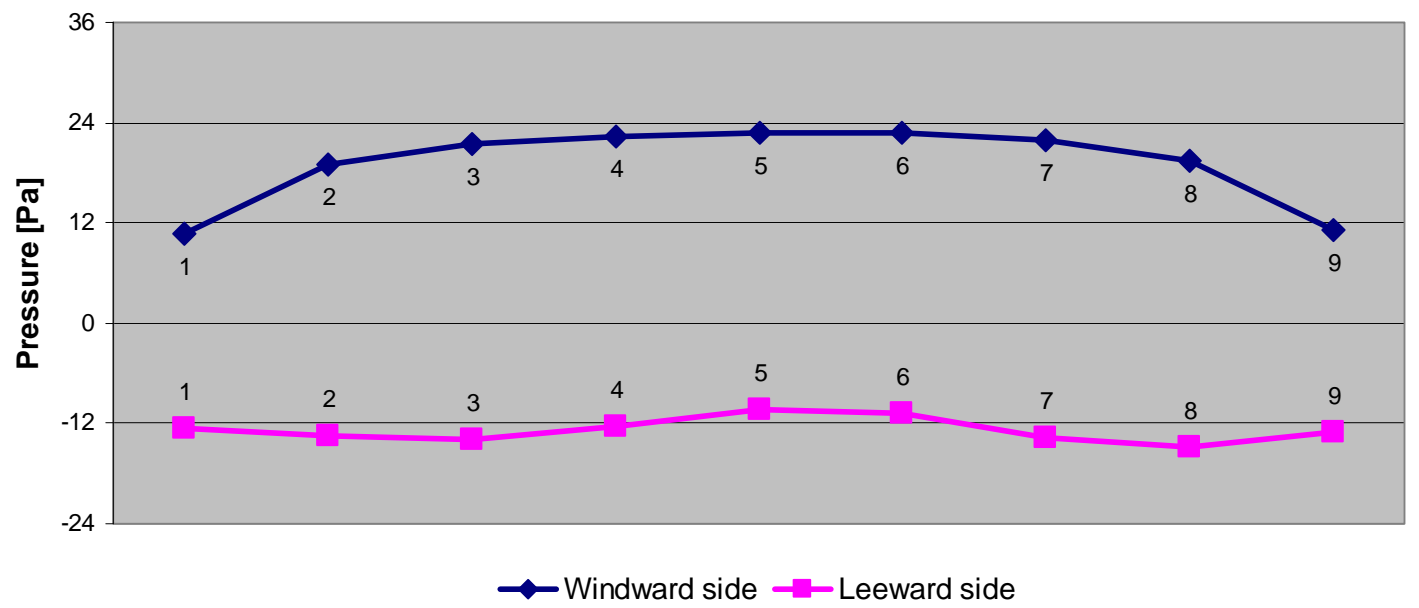

Figure 7: Pressures on holes [7] 
Secondly, the geometry of the underfloor air cavity with the intake and exhaust openings is independently modeled. Using 3D scanning and using graphic program Autodesk 3ds MAX simplified geometry Modulo H20 fitting was modeled. This simplified model was imported into ANSYS Design Modeler where the cavity to the results shape has been modeled. Geometric model is the air from inside of the cavity.

After deducting the windward and leeward pressures (Fig. 7) individual values are entered as input boundary conditions for the modeled cavity. To solution was used k-epsilon turbulence model. Solved total area consists of air at a temperature of $10^{\circ} \mathrm{C}$ (median of air temperature for the area of Košice). Boundary conditions are illustrated on Fig. 8. Specifically:

,inlet 1“- Boundary Type: Opening: Relative pressure $=1.18 \mathrm{~Pa}$

,inlet 2“- Boundary Type: Opening: Relative pressure $=2.38 \mathrm{~Pa}$

,inlet 3“ - Boundary Type: Opening: Relative pressure $=2.53 \mathrm{~Pa}$

„outlet 1“- Boundary Type: Outlet: Relative pressure $=-1.40 \mathrm{~Pa}$

„outlet 2“- Boundary Type: Outlet: Relative pressure $=-1.54 \mathrm{~Pa}$

,outlet 3“6 - Boundary Type: Outlet: Relative pressure $=-1.17 \mathrm{~Pa}$

„Modulo“6 - Boundary Type: Wall: No Slip Wall, Rough Wall = 0,0005 m

„PVC pipes“ - Boundary Type: Wall: No Slip Wall, Smooth Wall

„concrete base“ - Boundary Type: Wall: No Slip Wall, Rough Wall = 0,0005 m (rough concrete)

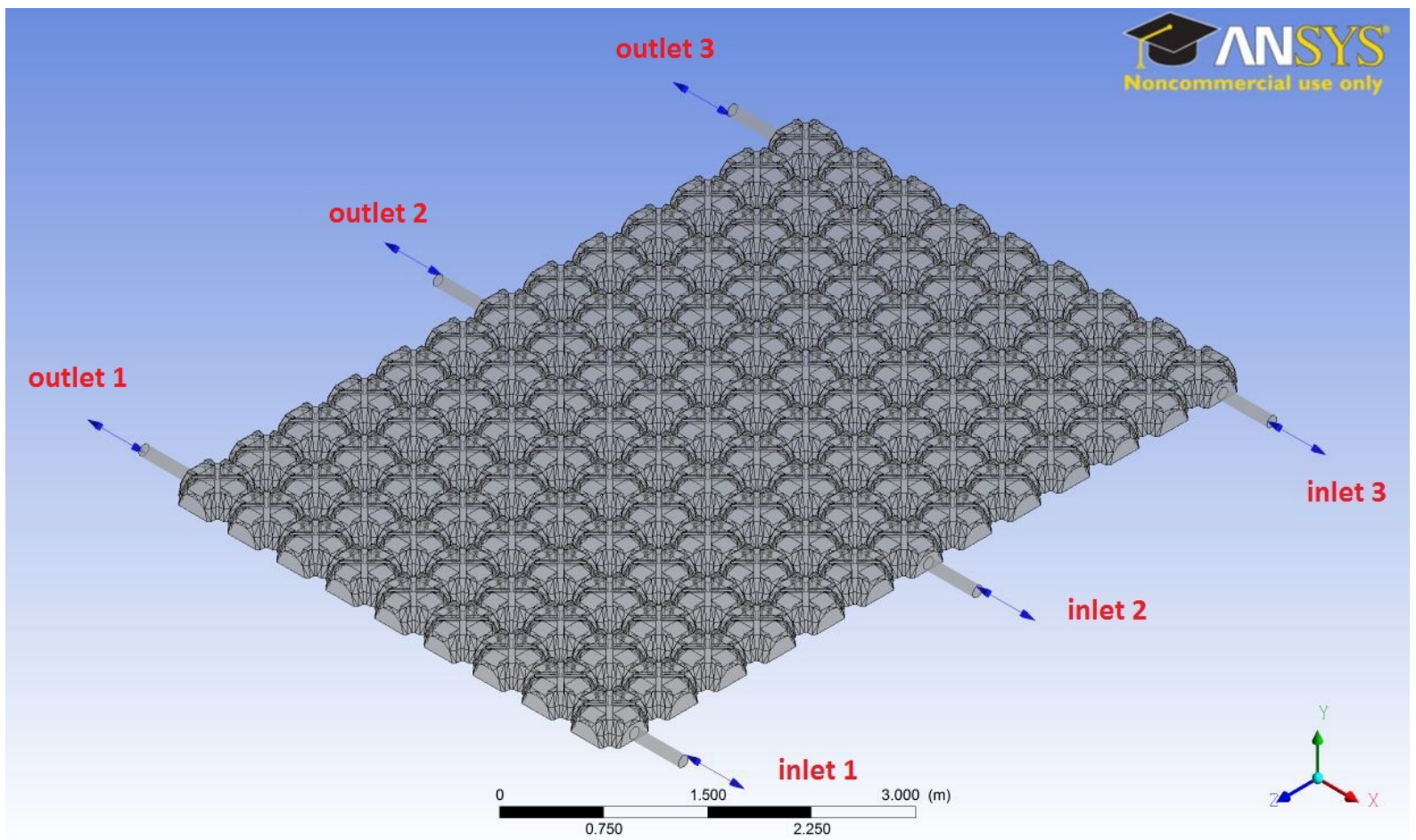

Figure 8: Second simulation model [7] 
In Fig. 9 an air velocity contour is produced along the longitudinal section of the openings axis within $0-1.81 \mathrm{~m} . \mathrm{s}^{-1}$ (global range). In Fig. 10 an air velocity contour is produced along longitudinal section of the plane $7 \mathrm{~mm}$ above the foundation within $0-0.1 \mathrm{~ms}^{-1}$ (a userspecified range for a better estimate of the actual flow). The average air velocity at the plane 7 $\mathrm{mm}$ above the foundation is $\mathbf{v}_{\mathbf{g}}=\mathbf{0 . 1} \mathbf{~ m s}^{-1}$.

Remark: Dimension of $7 \mathrm{~mm}$ corresponds to the intuitive estimate of the relevant distances from the foundation, to determine the air velocity (this value is fictional and will vary depend the subsoil).

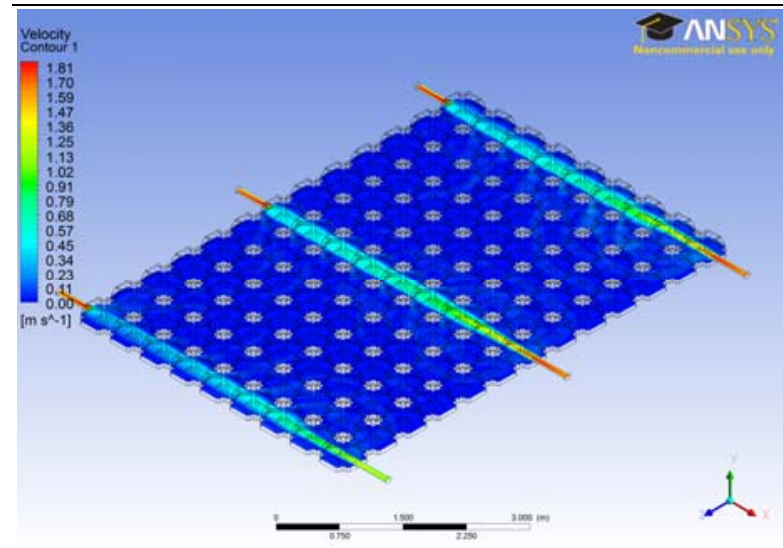

Figure 9: Design from manufacturers - Air velocity with global range [7]

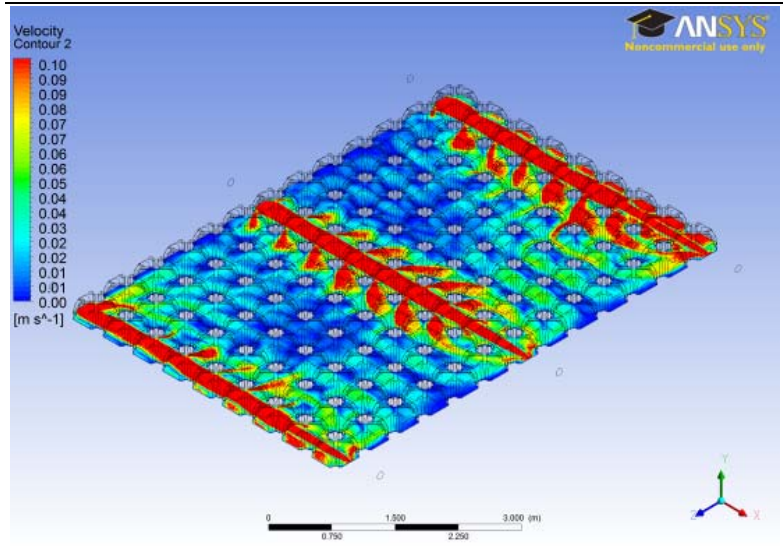

Figure 10: Design from manufacturers - Air velocity with user specified range [7]

Using simulation has been shown that the proposal for the layout of inlet and outlet openings by the manufacturer recommended (in the corners and at intervals of 3-5 m) is not ideal. Uneven distribution of air flow in the cavity in such design leads to. The air tends is to move one channel out from the cavity and the interstices remain practically unventilated. This effect is clearly evident already at intervals of vents at axial distances of $3 \mathrm{~m}$. At distances of $5 \mathrm{~m}$ will be zero effect of ventilation in the interstices unquestionable.

At direct way of airflow during the winter months to local cooling occurs. In future months, when is needed even distribution of airflow for the extraction of moisture from the subsoil flow is zero points. This results in the local accumulation of moisture (condensation) and thus in a negative effect, which is undesirable.

In general, for the proper function of the cavity (removing moisture) are not necessary big air velocity, but slow and even distribution of flow across the surface of the cavity so that there is no inversion effect - local accumulation of moisture in due to condensation.

Underfloor air cavities created using special fittings, as proposed by the manufacturers do not work ideal. The problem lies in the uneven distribution of airflow. To eliminate this negative situation will be developed four conceptual designs (simulation models) for the deployment of the air vents. In all of that there is the emphasis on the methodology of preservation of historical monuments and constructional possibilities of historic buildings. Differentiated treatment is affected by traditional construction technologies and also by the mechanical and physical properties of building materials. 


\section{Design KE 1}

The first simulation model is designed so that the individual intake / exhaust openings are located in the axial distance of $1000 \mathrm{~mm}$ (every second fitting). The idea is to eliminate points of zero airflow, respectively to achieve even distribution of air flow across of all cavity surfaces. Scheme of the proposal is shown in Fig. 11.

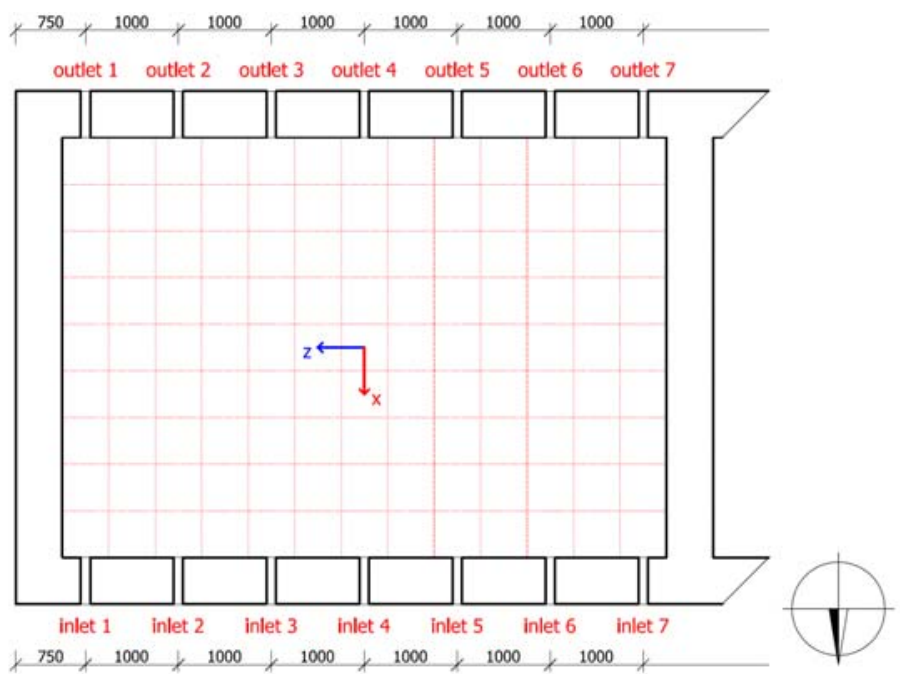

Figure 11: Design KE 1 [7]

The average air velocity at the plane $7 \mathrm{~mm}$ above the foundation is $\mathbf{v}_{\boldsymbol{ø}}=\mathbf{0 . 2} \mathbf{~ m s}^{\mathbf{- 1}}$. The distribution of air flow over the surface of cavity is evenly with higher average speed than in the case of Design from manufacturers. Air velocity contour are in Fig. 12 and Fig. 13.

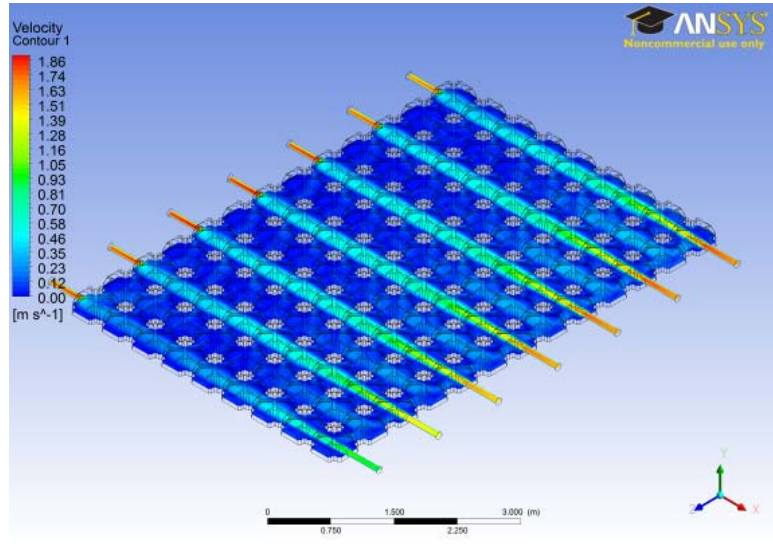

Figure 12: Design KE 1 - Air velocity with global range [7]

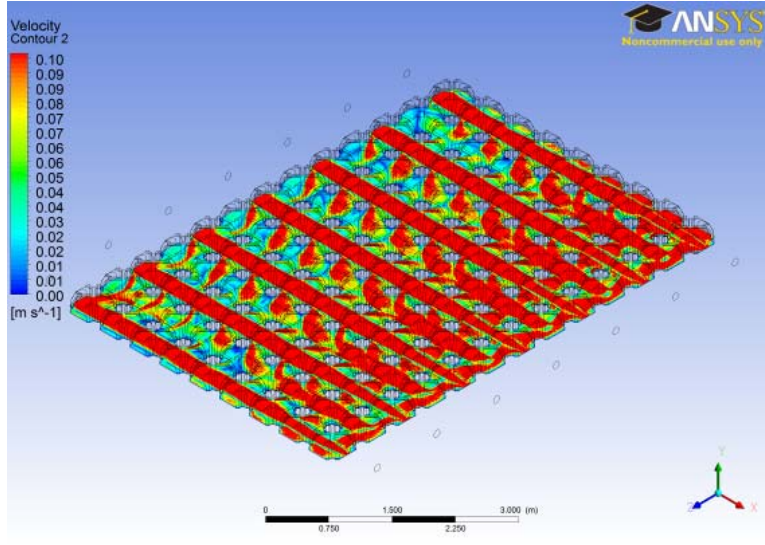

Figure 13: Design KE 1 - Air velocity with user specified range [7]

This model is suitable for implementation in the case of "high" dampness of subsoil and provided that static / monumental assessment of buildings allow it. 


\section{Design KE 2}

This simulation model is designed so that the individual intake / exhaust openings are located in the axial distance of $4000 \mathrm{~mm}$. Using PVC pipes and elbows are made "distributor (s)" with two inputs and five outputs. The function of the "distributor" is to split the incoming air into several "channels". Scheme of the proposal is shown in Fig. 14.

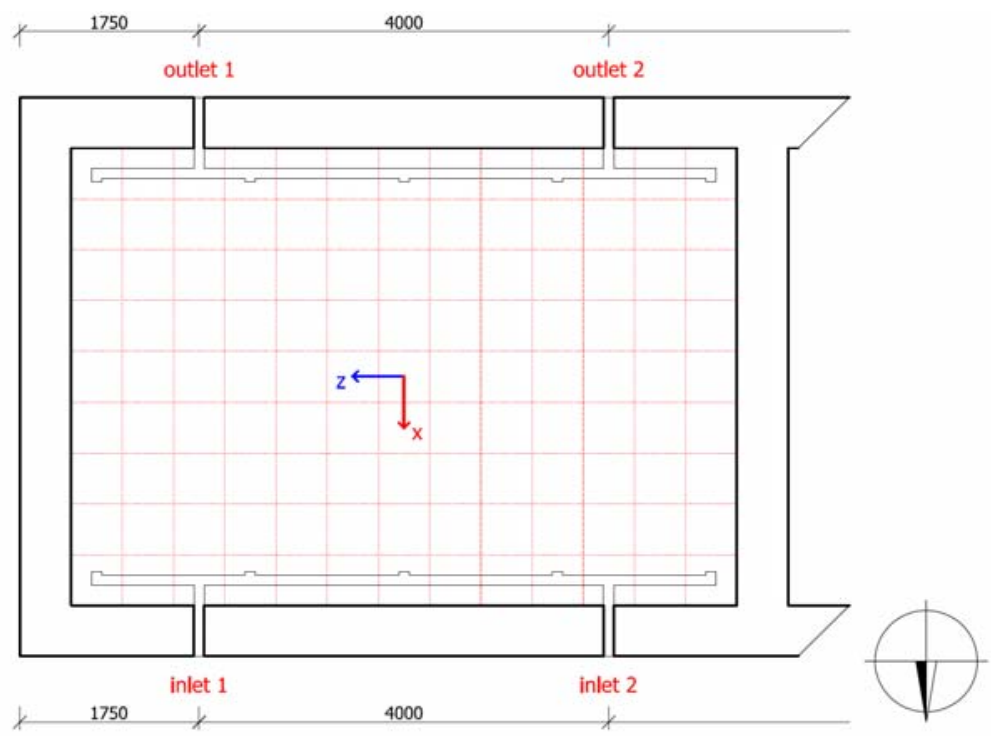

Figure 14: Design KE 2 [7]

The average air velocity at the plane $7 \mathrm{~mm}$ above the foundation is $\mathbf{v}_{\boldsymbol{g}}=\mathbf{0 . 0 5} \mathbf{~ m s}^{-1}$. The distribution of air flow over the surface of cavity is evenly, but at a lower average speed than in the case of Design from manufacturers. Air velocity contour are in Fig. 15 and Fig. 16.

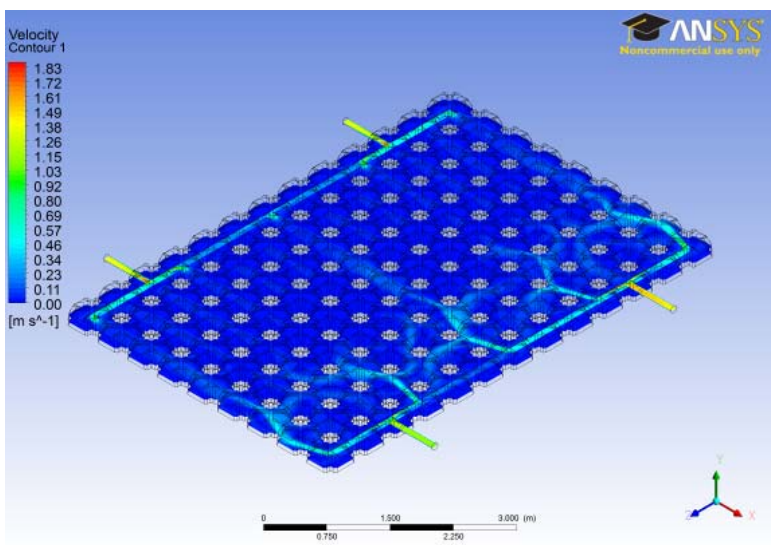

Figure 15: Design KE 2 - Air velocity with global range [7]

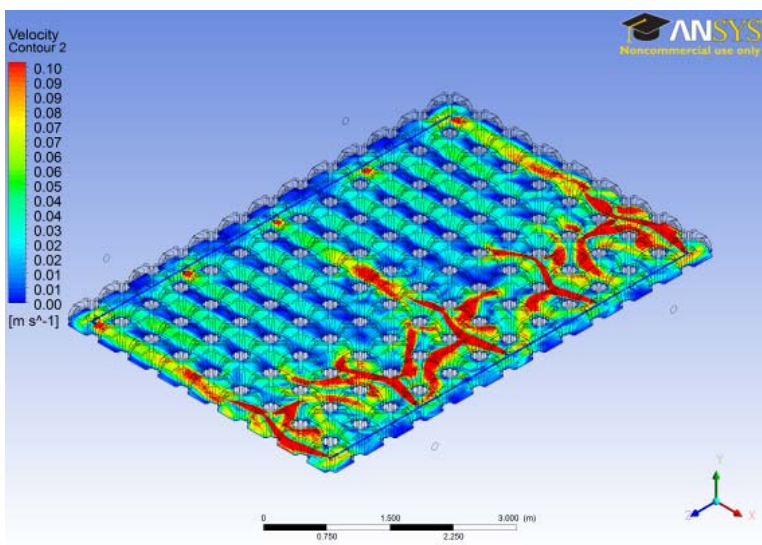

Figure 16: Design KE 2 - Air velocity with user specified range [7]

This method is suitable for implementation in the case of stricter static / monumental limiting the number of intake / exhausts holes and provided that the moisture of subsoil is "low". 


\section{Design KE 3}

The simulation model is designed so that the individual intake / exhaust openings are not in one straight line. The role of such an arrangement is deliberately split the incoming air to multiple locations cavity. Scheme of the proposal is shown in Fig. 17.

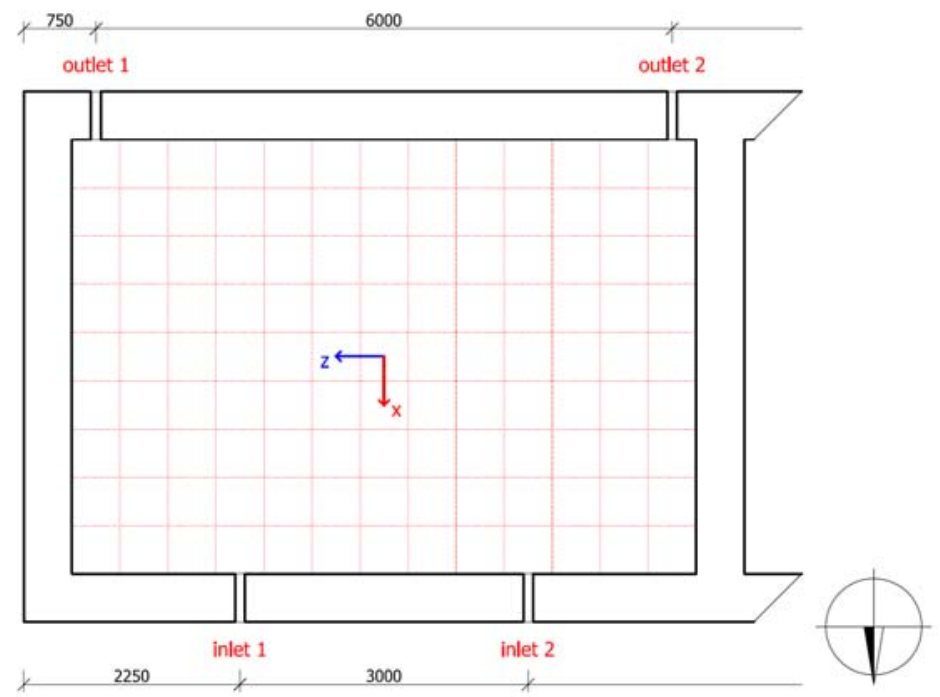

Figure 17: Design KE 3 [7]

The average air velocity at the plane $7 \mathrm{~mm}$ above the foundation is $\mathbf{v}_{\boldsymbol{0}}=\mathbf{0 . 0 8} \mathbf{~ m s}^{-1}$. The distribution of air flow over the surface of cavity is comparable to Design from manufacturers but at a lesser damage to masonry, with only the targeted layout of the ventilation openings. Air velocity contour are in Fig. 18 and Fig. 19.

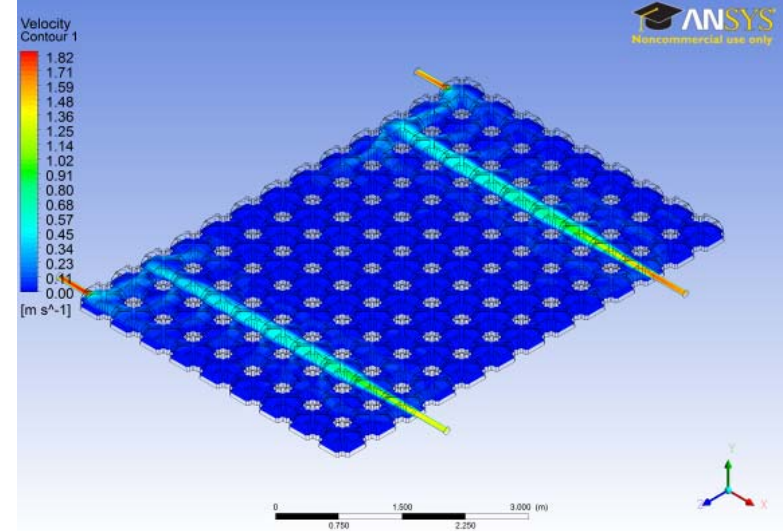

Figure 18: Design KE 3 - Air velocity with global range [7]

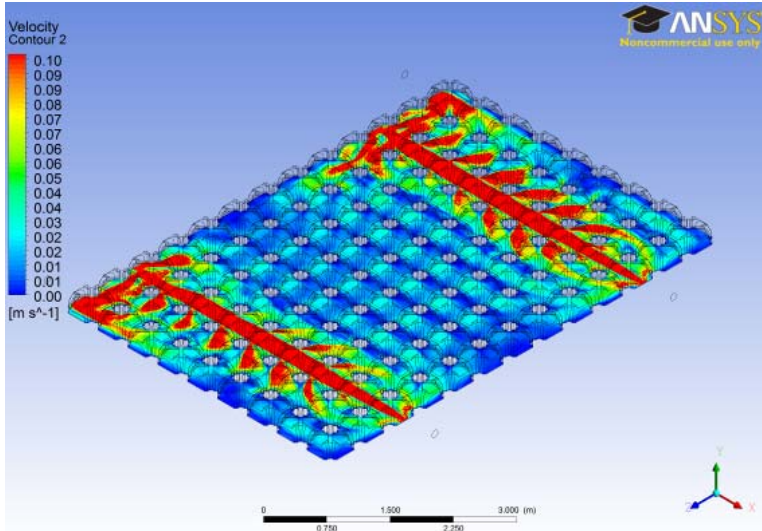

Figure 19: Design KE 3 - Air velocity with user specified range [7]

This method is suitable for implementation in the case of stricter static / monumental limiting and provided that the investor does not want to use a "distributor". 


\section{Conclusion}

The paper aims to highlight the possibilities of CFD computer simulation programs to assess airflow in underfloor cavities. The application of simple geometric models can confirm or refute the appropriateness of a proposed solution.

In this paper has been proposed layout of air vents for realization of underfloor air cavity created from special fittings. Simulations results differences in ventilated floors design become evident.

The role of the designer is individually choosing the best possible solution, respectively their combination, taking into account the static expression, taking into account the requirements of Monuments Board and taking into account the needs of air velocity in the cavity (yet intuitive).

In conclusion, I suggest focusing research on defining appropriate air velocity in the cavity depending on dampness + define the distance from the subsoil to the determination depending on the particular type of subsoil.

\section{Acknowledgements}

"This publication is the result of the Project implementation: The use of a virtual laboratory at designing energy-efficient buildings. Project 052TUKE-4/2013."

A special thanks to Mr. Jozef Farkaš and the ASUAN society, for providing Modulo fittings and its accessories.

\section{References}

[1] Benža et al. (1998) Folk architecture and urban planning of rural settlements in Slovakia. Bratos;ava: Academic Electronic Press, s. r. o. for National Conservation and Landscape Center.

[2] http://www.geoplast.it/eng/edilizia/modulo-system/index.html

[3] STN 73 0540-2. (2012). Thermal protection of buildings. Thermal performance of buildings and components. Part 2: Functional requirements. Slovak Republic.

[4] STN 73 0540-3. (2012). Thermal protection of buildings. Thermal performance of buildings and components. Part 3: Properties of environments and building products. Slovak Republic.

[5] STN EN ISO 13790/NA. (2010). Energy performance of buildings. Calculation of energy use for space heating and cooling (ISO 13790: 2008). National Annex. Slovak Republic.

[6] STN EN ISO 10211. (2008). Thermal bridges in building construction. Heat flows and surface temperatures. Detailed calculations. Slovak Republic.

[7] Renčko, T. (2013): Theoretically justified structural restoration of historic buildings. Dissertation work. Košice: Technical University in Košice, Civil Engineering Faculty. 